\title{
Anthropometric and biochemical correlates of PAPP-A2, free IGF-I, and IGFBP-3 in childhood
}

\author{
Masanobu Fujimoto ${ }^{1,2}$, Jane C Khoury ${ }^{1,3}$, Philip R Khoury4, Bhanu Kalra ${ }^{5}$, Ajay Kumar ${ }^{5}$, Patrick Sluss ${ }^{5}$, \\ Claus Oxvig', Vivian Hwa' ${ }^{1}$ and Andrew Dauber ${ }^{1,7,8}$
}

${ }^{1}$ Cincinnati Center for Growth Disorders, Division of Endocrinology, Cincinnati Children's Hospital Medical Center, University of Cincinnati College of Medicine, Cincinnati, Ohio, USA, ${ }^{2}$ Division of Pediatrics and Perinatology, Tottori University Faculty of Medicine, Yonago, Japan, ${ }^{3}$ Division of Biostatistics and Epidemiology, Cincinnati Children's Hospital Medical Center, University of Cincinnati College of Medicine, Cincinnati, Ohio, USA, ${ }^{4}$ Heart Institute Research Core, Cincinnati Children's Hospital Medical Center, University of Cincinnati College of Medicine, Cincinnati, Ohio, USA, ${ }^{5}$ Ansh Labs, Webster, Texas, USA, ${ }^{6}$ Department of Molecular Biology and Genetics, Aarhus University, Aarhus C, Denmark, ${ }^{7}$ Division of Endocrinology, Children's National Hospital, Washington, District of Columbia, USA, and ${ }^{8}$ Department of Pediatrics, George Washington University School of Medicine and Health Sciences, Washington, District of Columbia, USA

Correspondence should be addressed to A Dauber Email adauber@childrensnational. org

\begin{abstract}
Objective: Pregnancy-associated plasma protein-A2 (PAPP-A2) is a metalloproteinase that cleaves IGFBP-3 and IGFBP-5. Human mutations in PAPPA2 result in short stature with a low percentage of free IGF-I. Little is known about PAPP-A2 levels and the regulation of free IGF-I throughout childhood. We examined PAPP-A2 and intact IGFBP-3 levels in childhood and explored associations between PAPP-A2, free and total IGF-I, and total and intact IGFBP-3 and their relationship to the percentage of free to total IGF-I and anthropometric factors.

Design: Cross-sectional study at a single center.

Methods: PAPP-A2, free IGF-I, and intact IGFBP-3 levels were measured in childhood (3-18 years old) and an evaluation of the relationship between these proteins and anthropometric factors.

Results: In 838 children, PAPP-A2 consistently decreased throughout childhood. In contrast, free IGF-I increased. A pubertal peak in free IGF-I was present in females but was less evident in males. Intact and total IGFBP-3 increased throughout childhood; however, intact IGFBP-3 had a more marked rise than total IGFBP-3. Percent free IGF-I decreased with no distinct pubertal peak. PAPP-A2 levels positively correlated with the percent free IGF-I (Male, Female; $r=0.18,0.38 ; P<0.001$ ) and negatively with intact IGFBP-3 (Male, Female; $r=-0.58,-0.65 ; P<0.0001$ ). Conclusions: This is the first study to describe serum PAPP-A2 and intact IGFBP-3 in children between 3 and 18 years of age. Our correlative findings suggest that PAPP-A2 is an important regulator of the percent free IGF-I which can be a marker of perturbations in the GH/IGF-I axis.
\end{abstract}

\section{Introduction}

Growth hormone (GH) and insulin-like growth factor-I (IGF-I) play key roles in promoting normal growth. Genetic defects throughout the GH/IGF-I axis lead to a spectrum of growth disorders (1). GH induces production of IGF-I in the liver and at local target tissue such as the growth plate $(1,2)$. Additionally, GH stimulates liver production of IGF binding proteins (IGFBPs) and the acid-labile subunit (ALS) $(1,3,4)$. Total IGF-I, as well https://eje.bioscientifica.com https://doi.org/10.1530/EJE-19-0859 (c) 2020 European Society of Endocrinology Printed in Great Britain
Published by Bioscientifica Ltd. 
as IGFBP-3, are commonly used as clinical biomarkers in the evaluation of children with short stature. IGF-I is also frequently monitored during growth hormone treatment as a potential marker of safety $(5,6,7)$. Measurement of IGFBP-3 in serum is complicated due to the presence of cleaved IGFBP-3 fragments which are produced via proteolysis $(8,9)$. Most currently available commercial IGFBP-3 assays do not distinguish between the measurement of intact and fragmented IGFBP-3. It is possible that the lack of specificity of these assays for intact IGFBP-3 may contribute to the limited clinical utility of IGFBP-3 measurement in the diagnosis of GH deficiency (9).

In circulation, IGF-I and IGF-II predominantly exist in ternary complexes bound to ALS and IGFBP-3, as well as IGFBP-5, thereby prolonging the half-life of both IGFs $(1,3,10)$. In order to execute its growth promoting functions, IGF-I must be liberated from its ternary complexes into its free form, thereby allowing it to bind its cell surface receptor (11). Therefore, in addition to prolonging its half-life, IGFBPs play an active role in modulating IGF-I action through their regulation of the equilibrium between total and free IGF-I (3).

Recently, our group and others reported two families with loss-of-function mutations in PAPPA2 who presented with short stature accompanied by elevated total IGF-I, IGFBP-3, and GH levels and decreased ratio of free IGF-I to total IGF-I $(12,13)$. Pregnancy-associated plasma protein-A2 (PAPP-A2), one of the metzincin metalloproteinases, specifically cleaves IGFBP-3 and IGFBP-5, thereby liberating IGF-I from its ternary complex $(14,15)$. We postulate that by measuring the percentage of free to total IGF-I in the blood, this could serve as a proxy for PAPP-A2 activity. As the patients with mutations in PAPP-A2 have growth retardation, we hypothesize that this ratio could serve as a biomarker representing PAPPA2's effect on the equilibrium between total and free IGF-I and thus the potential availability of IGF-I to bind its receptor.

Previous work has demonstrated that PAPP-A2 levels increase with age in women and men as well as during the second trimester of pregnancy. $(16,17)$. However, little is known about PAPP-A2 concentrations throughout childhood. In the present report, we measured serum concentrations of total and free IGF-I, total and intact IGFBP-3, and PAPP-A2 in a large cross-sectional childhood cohort. The aim of this study was to generate curves for PAPP-A2 and intact IGFBP-3 concentration throughout childhood and to evaluate the relationship between these proteins and anthropometric factors.

\section{Subjects and methods}

\section{Study population and design of the Cincinnati Genomic Control Cohort}

The study subjects and data were derived from the Cincinnati Genomic Control Cohort (CGCC), which is a community-based cohort comprised of 1020 children representing the seven counties in Ohio and Kentucky surrounding Cincinnati in 2010. Subjects were between 3 and 18 years of age at the time of enrollment. The goal of the CGCC was to obtain a population representative sample which could be utilized as controls for a diverse set of projects. Data from this cohort have previously been published in studies of asthma $(18,19,20)$. Subjects were excluded from the CGCC if they meet any of the following criteria: presence of known genetic diseases or severe chronic medical conditions, first-degree relative participating in the project, unwillingness to complete family and personal health history, or allow storage for future analysis of samples. Written informed consent was obtained from the parent/legal guardian, and assent was obtained from the participants. The study was reviewed and approved by the institutional review board at Cincinnati Children's Hospital Medical Center. Recruitment of subjects and sample collections were completed in 2010.

\section{Study population and design of cross- sectional cohort}

Of the initial 1020 participants, 877 children between the age of 3 and 18 had sufficient serum samples available for the current study. Despite the GCC cohort being a generally healthy cohort, there were a number of children with a history of a medical condition which could theoretically affect growth. Therefore, we excluded all participants with severe obesity (BMI Z-score $>3.0$ S.D.) or undernutrition (BMI Z-score <-3.0 S.D.) and those with severe short stature (Height Z-score $<-3.0$ s.D.) or tall stature (Height Z-score $>3.0$ s.D.). Additionally, we excluded all patients with chronic diseases that could affect growth and one subject who was pregnant. The remaining 838 children were included in this study.

\section{Anthropometric data and samples}

As part of the initial cohort recruitment, all subjects had their height and weight measured twice and underwent a physical examination by a single investigator (21). Tanner staging for breasts in females and pubic hair development 
in both sexes were recorded. Genital Tanner staging was not performed in males. The CDC 2000 growth curves were used to calculate age- and sex-adjusted percentiles and Z-scores $(22,23)$. Non-fasting blood samples were collected in a serum separator tube from the participants at a single study visit. After clotting for a minimum of $30 \mathrm{~min}$, the blood samples were centrifuged at $1200 \mathrm{~g}$ for $10 \mathrm{~min}$ at room temperature. All serum samples were aliquoted and frozen at $-80^{\circ} \mathrm{C}$ within $2 \mathrm{~h}$ of collection. The serum samples were stored at $-80^{\circ} \mathrm{C}$ for more than 8 years without thawing until the current assays were performed.

\section{Hormonal measurement of total and free IGF-I, total and intact IGFBP-3, and PAPP-A2}

Serum concentrations of total and free IGF-I, total and intact IGFBP-3, and PAPP-A2 were measured using specific enzyme-linked immunosorbent assays (ELISAs) commercially available from Ansh Laboratories (Webster, TX, USA). All ELISAs were formatted as sandwichtype double-antibody assays that utilized monoclonal antibodies. Detailed methods and assay descriptions are provided in the Supplementary methods (see section on supplementary materials given at the end of this article).

\section{Analyte curve generation}

Age-specific curves were created for each variable separately by sex. Curves were developed using the $\mathrm{R}$ package: Generalized Additive Models for Location, Scale, and Shape (GAMLSS) (24). GAMLSS allows development of curves for a very wide range of distributions. Curve development was done using the Box-Cox $t$ (BCT) distribution, allowing models to be generated with a median, a coefficient of variation, and skewness and/or kurtosis. This is an extension of the lambda-mu-sigma (LMS) method, which models skewness, but not kurtosis, in the data. Briefly, this technique creates a distribution for each point on the x-axis, for example, age, which is informed by the data from surrounding points. The smoothing parameters used were P-splines or cubic splines. The final distributions and curves are arrived at by an iterative process. The adequacy of the models was assessed by examining model residuals using residual plots. Worm plots and $\mathrm{z}$ statistics were also used to determine if a given model was adequate across the entire age range. This method allows for the creation of a Z-score/percentile for each data point in the data set. Curves were constructed with the percentile lines of $5,10,25,50,75,90$, and 95th for each analyte (Figs 1, 2, 3, 4, 5, 6 and Supplementary
Tables 1, 2, 3, 4, 5, 6). Serum values of total and free IGF-I and PAPP-A2 were analyzed using log-transformed values which were then inverse transformed to calculate the centile table and curves.

\section{Statistical analysis}

Data were imported into SAS®, version 9.4 (SAS Institute, Cary NC), for data management and analysis. The dependent variables of interest were free IGF-I, total IGF-I, PAPP-A2, intact IGFBP-3, and total IGFBP-3. Continuous data were examined for distributional properties and potential outlying values. Three potential outliers were detected for free IGF-I, but after examination they were maintained in the data set for analysis. Three of the dependent variables, free IGF-I, PAPP-A2, and total IGF-I, were transformed using the natural logarithm for analysis.
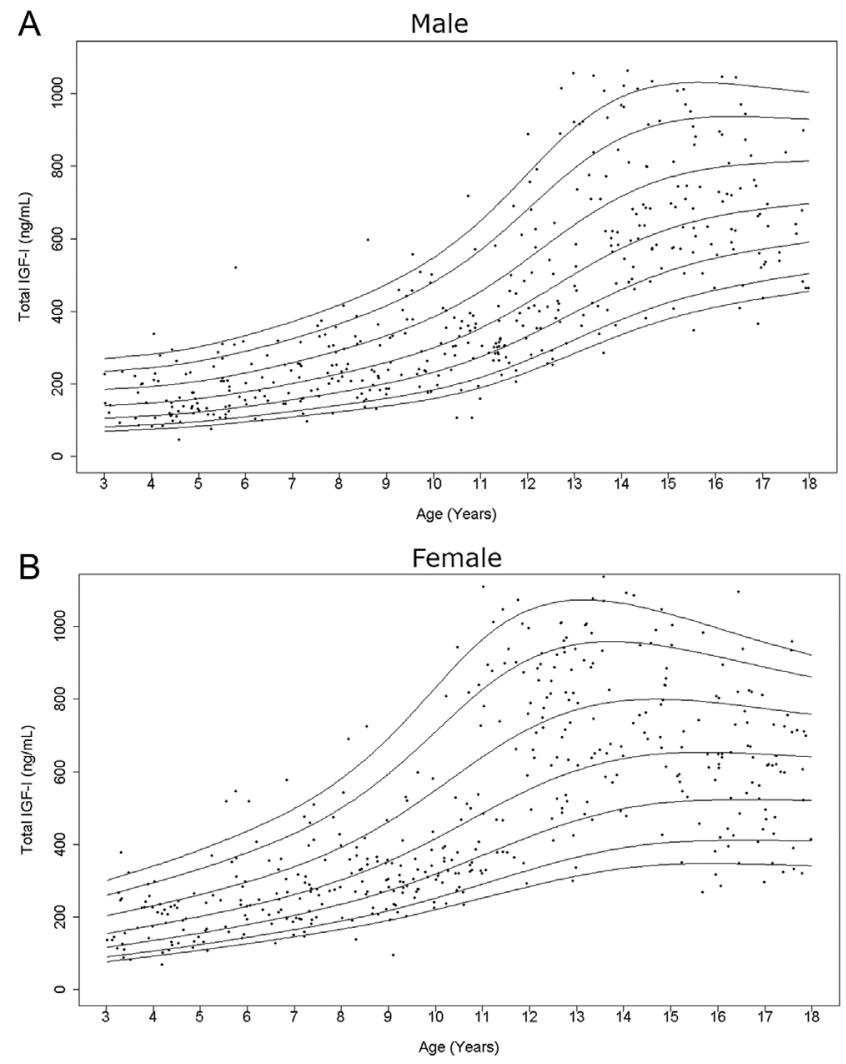

Figure 1

Cross-sectional measurements of serum total IGF-I in the study population. Age distribution of serum total IGF-I levels in males $(A)$ and females $(B)$ are represented respectively. The curves of the 5th, 10th, 25th, 50th, 75th, 90th, and 95th percentiles calculated by BCT method using the logtransformed values are displayed. 

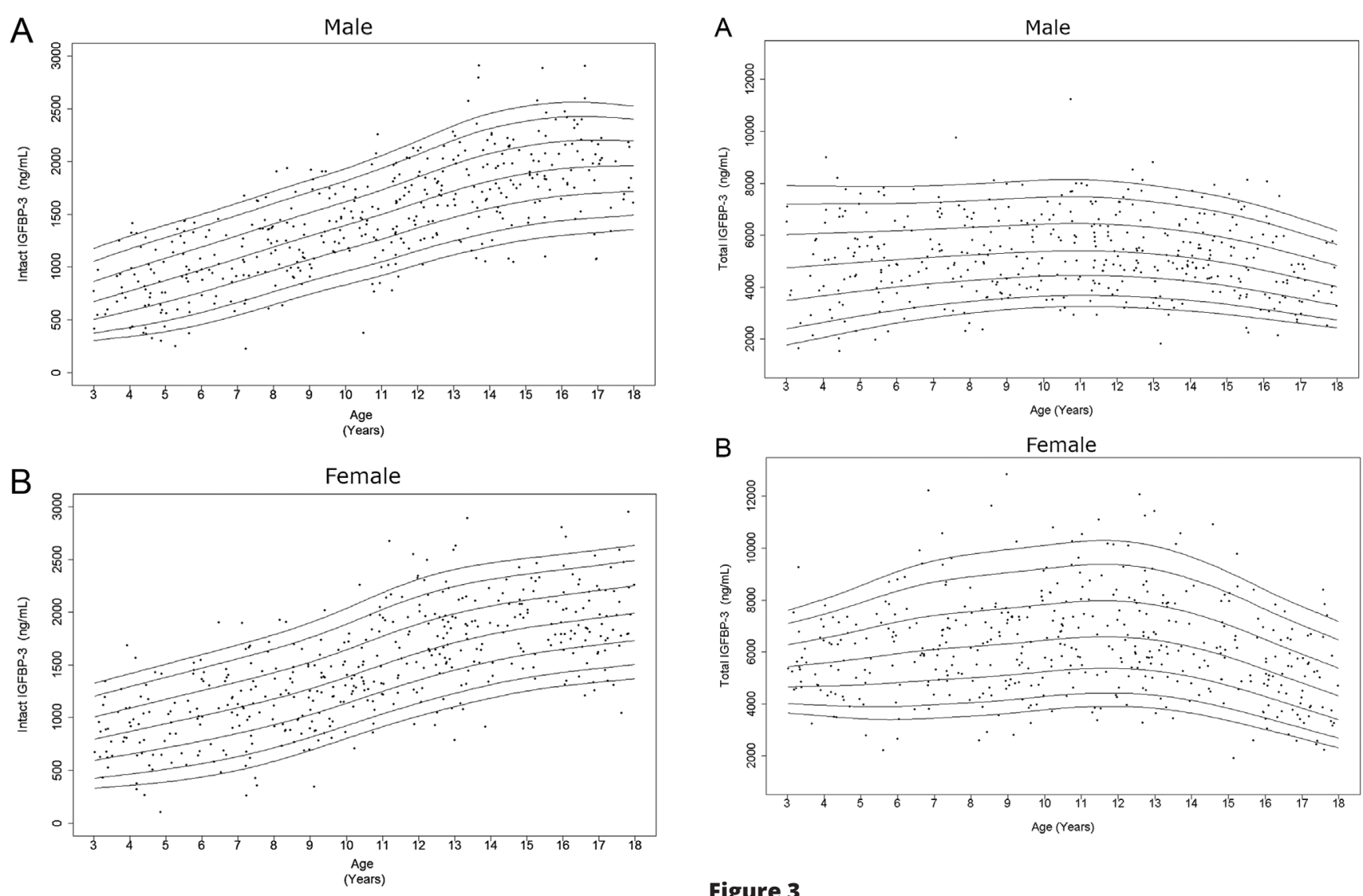

B

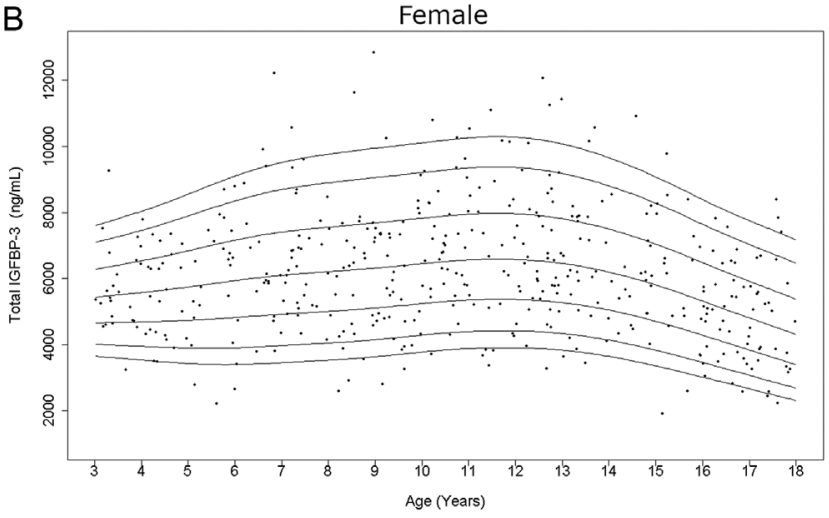

Figure 3

\section{Figure 2}

Cross-sectional measurements of intact IGFBP-3 in the study population. Age distribution of serum intact IGFBP-3 levels in males (A) and females (B) are represented respectively. The curves of the 5th, 10th, 25th, 50th, 75th, 90th, and 95th percentiles of intact IGFBP-3 value calculated by BCT method are displayed.

General linear models were used to examine changes over age for the dependent variables and differences by sex and the interaction of sex and age. If the interaction of age and sex was not significant, the model of just the main effects was examined. Further models were examined to include BMI Z-score and height Z-score, and both the Z-scores adjusted for age and sex were calculated using the CDC SAS program (https://www. cdc.gov/nccdphp/dnpao/growthcharts/resources/sas. $\mathrm{htm})$. Categorical variables are reported as number and percentage and continuous variables as mean (s.D.) or median and 25 th, 75 th percentile. Least square means and associated standard error are also reported, as appropriate. Pearson correlation was used to examine the association between the dependent variables. A $P$-value of $<0.05$ was considered statistically significant.

Cross-sectional measurements of serum total IGFBP-3 in the study population. Age distribution of serum total IGFBP-3 levels in males (A) and females (B) are represented respectively. The curves of the 5th, 10th, 25th, 50th, 75th, 90th, and 95 th percentiles of total IGFBP-3 value calculated by BCT method are displayed.

\section{Results}

\section{Study population}

Clinical and demographic features of the study population are summarized in Table 1 . The male to female distribution was consistent across all age ranges in the study. The majority of the population was Caucasian. There were no significant differences in height Z-score, weight Z-score, and BMI Z-score between males and females (Table 1).

\section{Childhood cohort-based curves for each analyte}

As expected, serum levels of total IGF-I and intact IGFBP-3 increased from early childhood into adolescence (Figs 1 and 2), while total IGFBP-3 showed only a slight rise prior to puberty (Fig. 3). After peaking during puberty, total IGF-I appeared to plateau and total IGFBP-3 slightly decreased 


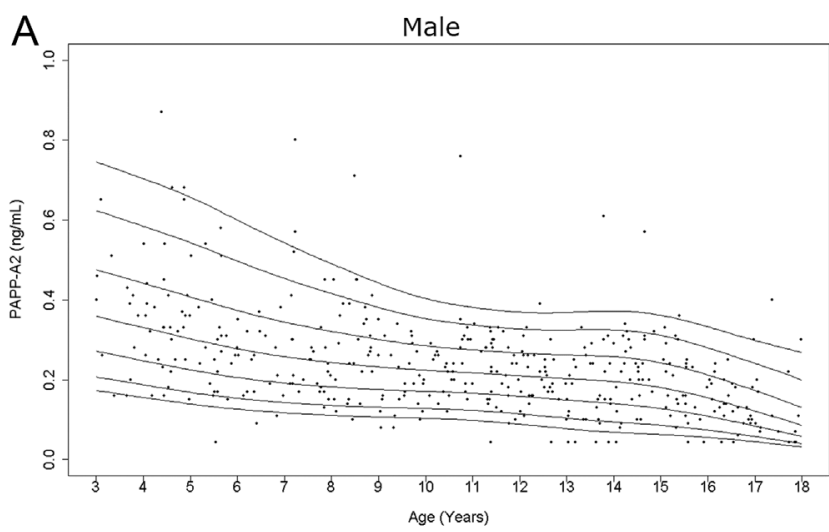

B

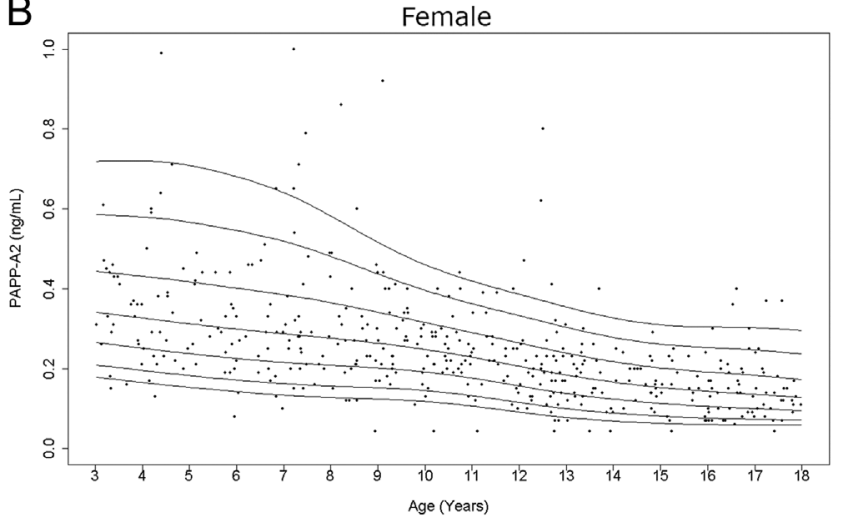

\section{Figure 4}

Cross-sectional measurements of serum PAPP-A2 in the study population. Age distribution of serum PAPP-A2 levels in males (A) and females (B) are represented respectively. The curves of the 5th, 10th, 25th, 50th, 75th, 90th, and 95th percentiles of PAPP-A2 value calculated by BCT method using the logtransformed values are displayed.

with increasing age. This finding is more prominent in the female curves. Interestingly, in contrast, intact IGFBP-3 levels continued to increase in the late teenage years and had a much more marked rise throughout childhood relative to total IGFBP-3.

Serum PAPP-A2 levels consistently decreased throughout childhood (Fig. 4). Free IGF-I levels increased with age, but to a lesser degree than total IGF-I levels (Fig. 5). There was a prominent pubertal increase in free IGF-I levels in girls (occurring at age 11-13 years), but this was not clearly seen in males. The hump of total and free IGF-I values (highest 50th percentile) tended to present slightly earlier in females than males (Supplementary Tables 1 and 2) as expected, due to earlier pubertal development in females.

We then calculated the percentage of free to total IGF-I (Fig. 6). Interestingly, this percentage significantly
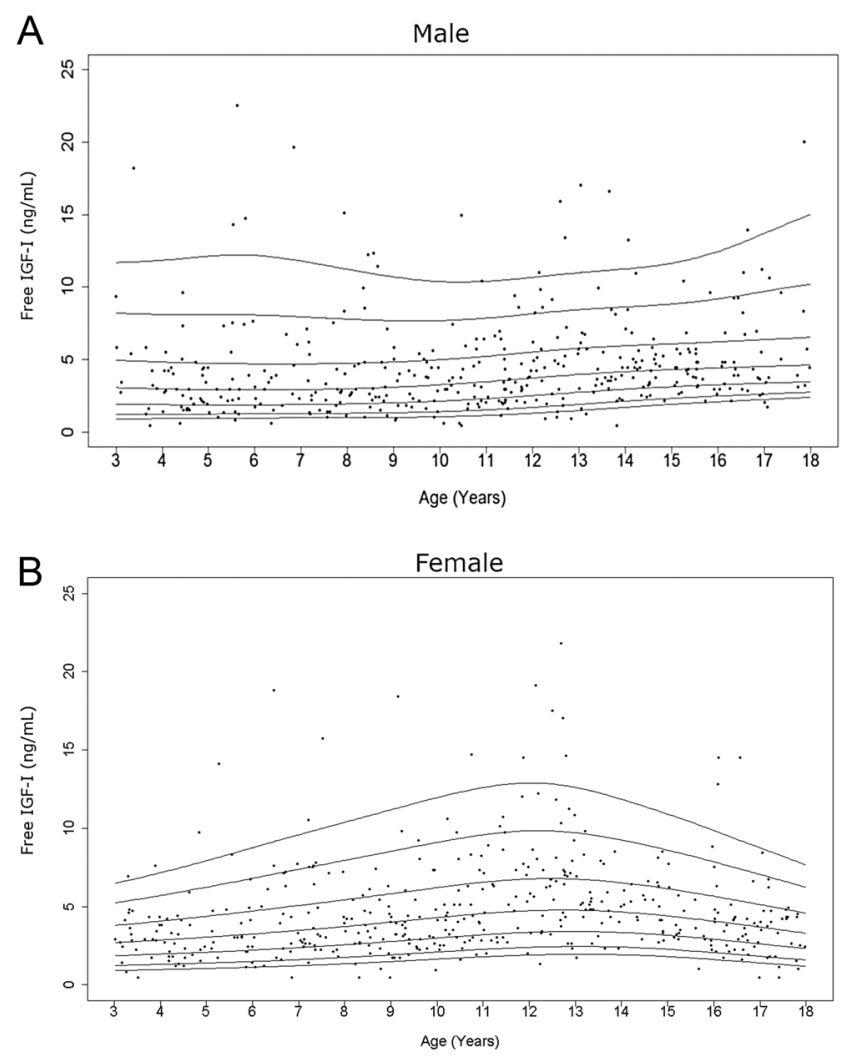

Figure 5

Cross-sectional measurements of serum free IGF-I in the study population. Age distribution of serum free IGF-I levels in males (A) and females (B) are represented respectively. The curves of the 5th, 10th, 25th, 50th, 75th, 90th, and 95th percentiles of free IGF-I value calculated by BCT method using the logtransformed values are displayed.

decreased with increasing age $(\beta=-0.122 \quad(0.030)$; $P<0.0001$ ) (Table 2), with no peak during the pubertal years. The 50th percentile for this percentage decreased from 2 to $0.66 \%$ in males and 1.6 to $0.55 \%$ in females from years 3-17 (Supplementary Table 6).

This initial analysis was performed based on age, as reliable pubertal staging data was only available in females based on breast evaluation and not in males who did not have genital staging performed. We performed a secondary analysis in females only based on Tanner Stage (Supplementary Table 7). This showed results consistent with the age-based analysis with total and free IGF-I as well as total IGFBP-3 levels peaking at Tanner stage 3 and subsequently falling. PAPP-A2 and the percentage of free IGF-I both progressively decreased with increasing Tanner stage, whereas intact IGFBP-3 levels progressively increased. 
A

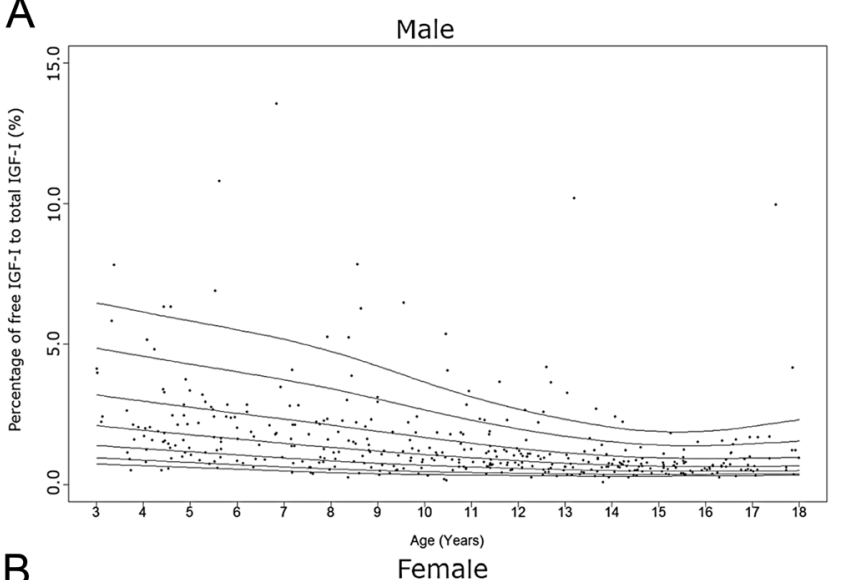

$B$

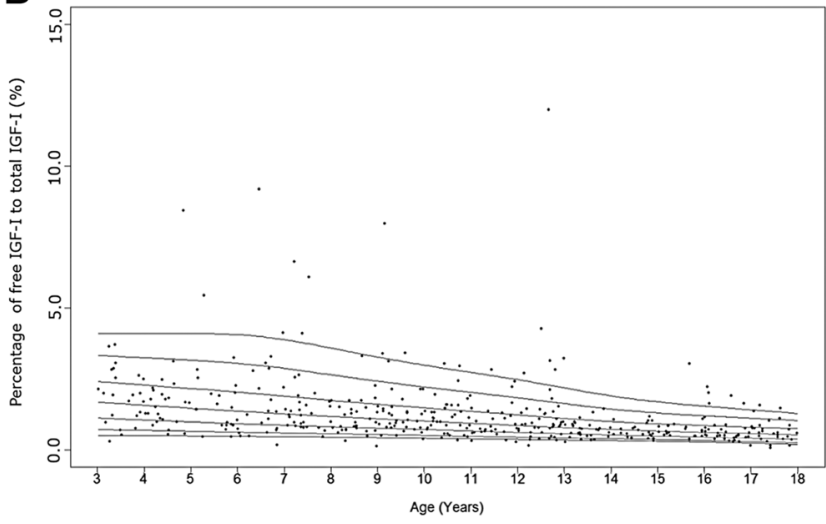

Figure 6

Cross-sectional measurements of the percentage of free IGF-I to total IGF-I in the study population. Age distribution of the percentage of free IGF-I to total IGF-I levels in males (A) and females (B) are represented respectively. The curves of the 5th, 10th, 25th, 50th, 75th, 90th, and 95th percentiles of the percentage of free IGF-I to total IGF-I level calculated by BCT method are displayed.

\section{Multivariate regression analysis of factors influencing hormonal values}

To determine clinical parameters associated with hormonal values of interest, we performed a multivariable regression analysis including age, sex, race, height, and BMI for each analyte (Table 2). As seen in the curves, total and free IGF-I and total and intact IGFBP-3 were all positively associated with age with a negative age-squared effect to account for the flattening of the curves or decreased analyte levels in later adolescence. PAPP-A2 had a negative association with age. Male sex was significantly negatively associated with total IGF-I and total IGFBP-3 but not with free IGF-I, intact IGFBP-3, or PAPP-A2 levels. African-American race was significantly associated with higher total IGF-I but lower intact and total IGFBP-3 levels. Height Z-score was
Table 1 Demographic and clinical characteristics of the study population $(n=838)$.

\begin{tabular}{|c|c|c|c|}
\hline Variable & All & Male & Female \\
\hline Sex, $n(\%)$ & & $405(48.3)$ & $433(51.7)$ \\
\hline \multicolumn{4}{|l|}{ Race, $n(\%)$} \\
\hline Caucasian & 698 (83.3) & 343 (84.7) & 355 (82.0) \\
\hline African-American & $125(14.9)$ & $58(14.3)$ & 67 (15.5) \\
\hline Other & $1(0.1)$ & $0(0)$ & $1(0.2)$ \\
\hline Unknown & $14(1.7)$ & $4(1.0)$ & $10(2.3)$ \\
\hline Height z-score, mean (s.D.) & $0.32(0.97)$ & $0.35(0.99)$ & $0.28(0.95)$ \\
\hline Weight z-score, mean (s.D.) & $0.51(0.97)$ & $0.52(0.99)$ & $0.49(0.94)$ \\
\hline BMI z-score, mean (s.D.) & $0.46(0.95)$ & $0.45(0.97)$ & $0.47(0.94)$ \\
\hline
\end{tabular}

positively associated with free and total IGF-I and intact and total IGFBP-3, but not with the ratio of free to total IGF-I. BMI Z-score was positively associated with total IGF-I and intact IGFBP-3 and negatively associated with PAPP-A2 and the ratio of free to total IGF-I.

\section{Correlation analysis between each analyte}

In order to further understand the physiological relationships between the various analytes, we examined correlations between the analytes by sex (Tables 3 and 4). Free IGF-I level was positively correlated with total IGF-I and the ratio of free to total IGF-I in both sexes. PAPP-A2 level had a weak negative correlation with free IGF-I $(r=-0.23, P<0.0001)$ in males only. As expected, given its role in cleavage of IGFBP-3, PAPP-A2 levels had a strong negative correlation with intact IGFBP-3 in both sexes. In addition, PAPP-A2 level was positively correlated with the ratio of free to total IGF-I in both sexes with a stronger association in females suggesting that PAPP-A2 levels do correlate with the percentage of free IGF-I. However, unexpectedly, PAPP-A2 levels were positively correlated with total IGFBP-3 in both sexes, although not in a linear fashion (Supplementary Fig. 1). Additionally, PAPP-A2 levels had a negative correlation with total IGF-I in both sexes. Interestingly, intact IGFBP-3, but not total IGFBP-3, had a strong negative correlation with the ratio of free to total IGF-I in both sexes (Males and Females: $r=-0.53, P<0.0001)$. Intact IGFBP-3 was highly positively correlated with total IGF-I in both sexes. While total IGFBP-3 had no significant correlation with free and total IGF-I in males, there was a weak but significant correlation in females.

As these results suggested that PAPP-A2 and intact IGFBP-3 have an effect on the percentage of free to total IGF-I, we performed additional multivariate regression analyses to assess the contribution of each of these analytes in determining absolute free IGF-I as well as the 
Table 2 Multivariate regression analysis for free and total IGF-I, PAPP-A2, intact and total IGFBP-3, and ratio of free to total IGF-I.

\begin{tabular}{l}
\hline Variable \\
\hline Free IGF-|' \\
Age \\
Age $^{2}$ \\
Male \\
African-American \\
BMI Z-score \\
Height Z-score \\
Total IGF-Ia \\
Age \\
Age \\
Male \\
African-American \\
BMI Z-score \\
Height Z-score \\
PAPP-A2 \\
Age \\
Male \\
African-American \\
BMI Z-score \\
Height Z-score \\
Intact IGFBP-3 \\
Age \\
Age \\
Male \\
African-American \\
BMI Z-score \\
Height Z-score \\
Total IGFBP-3 \\
Age \\
Age \\
Male \\
African-American \\
BMI Z-score \\
Height Z-score \\
Age \\
Male \\
African-American \\
BMI Z-score \\
Height Z-score \\
\hline
\end{tabular}

\begin{tabular}{c}
\hline $\boldsymbol{\beta}$ \\
\hline 0.108 \\
-0.004 \\
-0.076 \\
-0.076 \\
-0.016 \\
0.064
\end{tabular}

$\longrightarrow$

$\mathbf{S E}_{\mathbf{B}}$

0.03

0.001

0.047

0.024

0.026

0.025

0.23

$-0.0056$

$-0.194$

0.129

0.048

0.11

$$
-0.07
$$

$-0.032$

0.052

$-0.11$

$-0.033$

128

$-1.79$

$-15.8$

$-112$

94.9

65.4

539.6

$-28.2$

$-1007.8$

$-569.4$

$-80.6$

177.6

$-0.122$

0.12

$-0.12$

$-0.06$

$-0.04$
0.016

0.008

0.025

0.036

0.014

0.013

0.004

0.033

0.047

0.018

0.018

15.4

0.75

24

33.9

13

12.7

73.4

3.58

114.3

161.4

61.9

60.7

0.03

0.05

0.06

0.02

0.02

\begin{tabular}{l}
\hline P value \\
\hline 0.0004 \\
0.01 \\
0.11 \\
0.83 \\
0.54 \\
0.01
\end{tabular}

Adjusted $\mathbf{R}^{2}$

0.05

$<0.001$

$<0.0001$

$<0.0001$

0.0003

0.0005

$<0.0001$

$<0.0001$

0.29

0.33

0.27

$<0.0001$

0.06

$<0.0001$

0.02

0.51

0.001

$<0.0001$

$<0.0001$

$<0.0001$

$<0.0001$

$<0.0001$

0.0004

0.19

0.004

$<0.0001$

0.01

0.07

0.01

0.07

aThe natural log-transformation was used for statistical analysis of free and total IGF-I, PAPP-A2 and percentage of free to total IGF-I. $\beta$, adjusted regression coefficient; $\mathrm{SE}_{\beta}$, standard error of the coefficient.

percentage of free to total IGF-I (Supplementary Table 8). Addition of neither PAPP-A2 nor intact IGFBP-3 had a significant effect on absolute free IGF-I ( $P$-values of 0.95 and 0.81 ). However, addition of each analyte to the free to total IGF-I model was significant ( $P$-values of 0.002 and $<0.001$ ). Addition of PAPP-A2 had a negligible effect on the R-squared value, but addition of intact IGFBP-3 increased the R-squared value from 0.23 to 0.3 . These data support the notion that PAPP-A2 and intact IGFBP-3 play a role in regulating the percentage of free IGF-I, but they alone are not the sole determinants of this ratio.

\section{Discussion}

Recently, the first human pathogenic mutations in PAPPA2 resulting in progressive postnatal growth retardation due to decreased IGF-I bioavailability were identified (12). The two families demonstrated the critical role of PAPP-A2 in regulating IGF-I action and secondarily growth in childhood. However, there are no data on PAPP-A2 levels throughout childhood, and there have been no studies examining the relationship between PAPP-A2 levels and levels of IGF-I and its binding proteins throughout childhood. In this study, we sought to describe trends in 
Table 3 Cross-sectional bivariate Pearson correlation between free IGF-I, total IGF-I, PAPP-A2, intact IGFBP-3, and total IGFBP-3 in males.

\begin{tabular}{|c|c|c|c|c|c|}
\hline Variable & Total IGF-|'a & PAPP-A2 $^{\mathbf{a}}$ & Intact IGFBP-3 & Total IGFBP-3 & $\begin{array}{c}\text { Percentage of free to } \\
\text { total IGF-|' }\end{array}$ \\
\hline \multicolumn{6}{|c|}{ Free IGF-I $(n=402)^{a}$} \\
\hline$R$ & 0.32 & -0.23 & 0.17 & -0.07 & 0.65 \\
\hline$P$ value & $<0.0001$ & $<0.0001$ & 0.0005 & 0.14 & $<0.0001$ \\
\hline \multicolumn{6}{|c|}{ Total IGF-I $(n=405)^{a}$} \\
\hline$R$ & & -0.48 & 0.85 & 0.02 & -0.51 \\
\hline$P$ value & & $<0.0001$ & $<0.0001$ & 0.72 & $<0.0001$ \\
\hline \multicolumn{6}{|c|}{ PAPP-A2 $(n=405)^{a}$} \\
\hline r & & & -0.58 & 0.25 & 0.18 \\
\hline$P$ value & & & $<0.0001$ & $<0.0001$ & 0.0004 \\
\hline \multicolumn{6}{|c|}{ Intact IGFBP-3 $(n=405)$} \\
\hline$r$ & & & & -0.06 & -0.53 \\
\hline$P$ value & & & & 0.25 & $<0.0001$ \\
\hline \multicolumn{6}{|c|}{ Total IGFBP-3 $(n=405)$} \\
\hline$R$ & & & & & -0.08 \\
\hline$P$ value & & & & & 0.11 \\
\hline
\end{tabular}

aThe natural log-transformation was used for statistical analysis of free and total IGF-I, PAPP-A2, and percentage of free to total IGF-I.

serum PAPP-A2, free IGF-I, and intact IGFBP-3 throughout childhood and examine association with demographic and anthropometric factors as well as total IGF-I and IGFBP-3 levels. Furthermore, we explored the regulation of free IGF-I throughout childhood by PAPP-A2, measured as the percentage of free to total IGF-I, and examined the correlation with measured hormonal levels.

IGF-I is an important surrogate marker for GH action. It is used in routine clinical practice as a biomarker of GH deficiency or resistance and is routinely monitored in patients receiving $\mathrm{GH}$ treatment $(5,25)$. There are well established normative ranges for total IGF-I levels throughout life, including childhood (26). The peak values of total IGF-I from different studies were observed at $13-15$ years of age and approximately $1-2$ years earlier for females compared with males $(26,27,28,29,30)$. The same trends were evident in our data, therefore, supporting the validity of our samples and the comparability of our patient population to previously reported populationbased studies.

In contrast to total IGF-I, data on free IGF-I levels in childhood are relatively limited. Similar to previous results $(28,31,32)$, the free IGF-I level in females increased with age and peaked in puberty. However, the peak was much

Table 4 Cross-sectional bivariate Pearson correlation between free IGF-I, total IGF-I, PAPP-A2, intact IGFBP-3, and total IGFBP-3 in females.

\begin{tabular}{|c|c|c|c|c|c|}
\hline Variable & Total IGF-Ia & PAPP-A2 ${ }^{a}$ & Intact IGFBP-3 & Total IGFBP-3 & $\begin{array}{c}\text { Percentage of free to } \\
\text { total IGF-Ia }\end{array}$ \\
\hline \multicolumn{6}{|c|}{ Free IGF-I $(n=431)^{\mathrm{a}}$} \\
\hline$R$ & 0.39 & -0.03 & 0.12 & 0.27 & 0.61 \\
\hline$P$ value & $<0.0001$ & 0.59 & 0.01 & $<0.0001$ & $<0.0001$ \\
\hline \multicolumn{6}{|c|}{ Total IGF-I $(n=431)^{\mathrm{a}}$} \\
\hline$r$ & & -0.47 & 0.75 & 0.10 & -0.49 \\
\hline$P$ value & & $<0.0001$ & $<0.0001$ & 0.04 & $<0.0001$ \\
\hline \multicolumn{6}{|c|}{ PAPP-A2 $(n=431)^{\mathrm{a}}$} \\
\hline$R$ & & & -0.65 & 0.29 & 0.38 \\
\hline$P$ value & & & $<0.0001$ & $<0.0001$ & $<0.0001$ \\
\hline \multicolumn{6}{|c|}{ Intact IGFBP-3 $(n=431)$} \\
\hline$R$ & & & & -0.14 & -0.53 \\
\hline$P$ value & & & & 0.003 & $<0.0001$ \\
\hline \multicolumn{6}{|c|}{ Total IGFBP-3 $(n=431)$} \\
\hline$R$ & & & & & 0.17 \\
\hline$P$ value & & & & & 0.0003 \\
\hline
\end{tabular}

The natural log-transformation was used for statistical analysis of free and total IGF-I, PAPP-A2, and percentage of free to total IGF-I. 
less evident in males. Additionally, the degree of rise of free IGF-I throughout childhood was not as dramatic as for total IGF-I in our study. Hence, circulating free IGF-I levels alone likely do not add much diagnostic utility above a routine total IGF-I level, as has been noted in previous studies $(32,33)$. The percentage of free to total IGF-I, however, was of interest as it could be a proxy for the regulation of IGF-I and its interaction with its binding proteins. This percentage, moreover, allows us to examine the role of PAPP-A2 and IGFBP-3 in regulating free IGF-I in circulation and could be a marker of perturbations in the growth hormone/IGF-I axis as was seen in the patients with genetic defects in PAPPA2 (12). Interestingly, our results indicated that the percentage of free to total IGF-I decreased through childhood. Previous studies have shown higher levels of this ratio in early infancy and pregnancy $(28,34,35)$, which have been attributed to increased IGFBP-3 proteolytic activity. In another study examining free IGF-I in healthy children between the ages of $8-15$, the percentage of free to total IGF-I was significantly higher during the pubertal years due to a relatively greater increase in total IGF-I as compared to IGFBP-3 (31). Comparisons across the different studies, however, are confounded by different assay methodologies used to measure free and total IGF-I. In the current study, the percentage of free to total IGF-I was not significantly associated with height Z-score, but it clearly correlated with a number of other hormonal measurements including PAPP-A2 and intact IGFBP-3 levels. Of course, as the current study is crosssectional in nature, we are unable to determine if this value predicts future height potential.

In circulation, the majority of IGF-I is bound to IGFBP-3 and ALS in order to prolong its half-life (36). Total IGFBP-3 levels have been thoroughly studied in population-based studies, including in childhood. However, to our knowledge, no prior studies have examined intact vs total IGFBP-3 levels in a populationbased study and certainly not in childhood. Prior ELISAs were unable to distinguish intact IGFBP-3 from its cleaved forms. The total IGFBP-3 levels (50th percentile) in our data had similar trends with previous reports, including a higher peak total IGFBP-3 level in females than males (37). Interestingly, there was no difference in intact IGFBP-3 levels between the two sexes. As expected, intact IGFBP-3 levels, but not total IGFBP-3, had a negative correlation with the percentage of free IGF-I. Similarly, only intact IGFBP-3 levels demonstrated a strong positive correlation with total IGF-I levels, both of which are GH-dependent factors. Taken together, these findings suggest that intact IGFBP-3 more accurately reflects the biologically significant binding protein function than total IGFBP-3 and raises the possibility that intact IGFBP-3 could be a better diagnostic biomarker in the evaluation of GH-related disease and monitoring of therapy. Of note, previous studies have called into question the diagnostic utility of total IGFBP-3 measurement $(25,38,39)$.

PAPP-A2 protein is detectable at high levels in human serum during pregnancy and increases from the first trimester to the third trimester presumably due to the fetal need for high levels of free IGF-I (40). Previous studies examining PAPP-A2 levels in the adult population (20-70 years) noted that females had slightly higher mean PAPP-A2 levels than males with PAPP-A2 levels being positively correlated with age (17). Our data also showed slightly higher PAPP-A2 levels in females than males, but levels were negatively associated with age. These findings suggest that PAPP-A2 concentration follows a U-shaped curve throughout a lifetime with higher levels in infancy which fall throughout childhood prior to increasing again in adulthood. PAPP-A2 levels were positively correlated with the percentage of free to total IGF-I which was likely mediated through their strong negative correlation with intact IGFBP-3 levels, suggesting that decreased PAPP-A2 concentrations may be the reason for the fall in free IGF-I percentage throughout childhood. In a similar study, Renes et al. demonstrated that serum IGFBP-3 proteolytic activity decreased with age during childhood with no apparent peak during puberty (41), consistent with our results. Although their study did not elucidate the factor behind the IGFBP-3 proteolytic activity, it is reasonable to hypothesize that PAPP-A2 may have been responsible.

Our study has a number of limitations. First, this is a cross-sectional study with subjects only being evaluated at a single visit. Thus, we have no ability to comment on final adult height or the correlation of any variable with growth velocity. Second, as this study only examined children between the ages of 3-18, we cannot compare our data on the percentage of free IGF-I to studies of younger children or adults. Additionally, reliable pubertal staging data was only available for females and thus our ability to perform a reliable correlation analysis with pubertal development was quite limited. This is a significant weakness, as pubertal hormones are known to have a major effect on growth and the GH/IGF-I system. Another important point is that the statistical methods used to generate the normative curves rely on all of the data points surrounding a specific age. As a result, the percentile curves are less reliable at the edges (i.e. at the ages of 3 and 18) which explains why some of the curves flare out at the ends. Third, Frystyk et al. have reported that there is an inverse relationship between 
IGFBP-1 and free IGF-I levels (42) but that there was no significant association between IGFBP-1 and bioactive IGF-I levels for adult women (43). Unfortunately, we have no data of IGFBP-1 or insulin in our serum samples. In addition, our data were derived largely from a Caucasian population. Finally, the samples used in this study were frozen for a number of years prior to analysis. However, the similarity of our data to previously published results and the strong biological correlations in the data suggest that the analysis is sound. The strength of the study is the relatively large population and the even distribution of samples throughout the age range.

In conclusion, this study describes serum PAPP-A2 and intact IGFBP-3 levels in children between 3 and 18 years of age. PAPP-A2 and the percentage of free to total IGF-I decrease with age. Our findings suggested that PAPP-A2 plays an important role in regulating the percentage of free to total IGF-I throughout childhood, a potential proxy for the ability of IGF-I to bind to its receptor. Further studies are needed to reveal the mechanisms underlying the regulation of the interaction between PAPP-A2, IGF binding proteins, and free IGF-I. Measurement of intact IGFBP-3 may be a more clinically meaningful biomarker than currently used total IGFBP-3 assays.

\section{Supplementary materials}

This is linked to the online version of the paper at https://doi.org/10.1530/ EJE-19-0859.

\section{Declaration of interest}

B K, A K, and P S are employees of Ansh Laboratories. A D and $\mathrm{VH}$ have a patent for the use of recombinant PAPPA2 as a growth promoting agent. The other authors have nothing to disclose.

\section{Funding}

This research was supported in part by the Cincinnati Children's Research Foundation and the Cincinnati Genomic Control Cohort.

\section{Author contribution statement}

M F and A D designed the study, designed and contributed to the analysis, and wrote the initial manuscript draft. B K, A K, and P S designed and performed the assays and performed the analysis. J K and $\mathrm{P} K$ performed statistical analysis and generated the curves. $\mathrm{V} \mathrm{H}$ and $\mathrm{C} \mathrm{O}$ reviewed the data and contributed to the analysis. All authors discussed the results and contributed to the final manuscript.

\section{Acknowledgments}

The authors thank Lisa Martin and Susan Thompson and the entire Cincinnati Genomics Control Cohort team for providing the samples for the study. The authors also thank Melissa Andrew and Leah Tyzinski in the Division of Endocrinology, Cincinnati Children's Hospital Medical Center, for their assistance with sample handling.

\section{References}

1 David A, Hwa V, Metherell LA, Netchine I, Camacho-Hubner C, Clark AJ, Rosenfeld RG \& Savage MO. Evidence for a continuum of genetic, phenotypic, and biochemical abnormalities in children with growth hormone insensitivity. Endocrine Reviews 201132 472-497. (https://doi.org/10.1210/er.2010-0023)

2 Savage MO, Hwa V, David A, Rosenfeld RG \& Metherell LA. Genetic defects in the growth hormone-IGF-I axis causing growth hormone insensitivity and impaired linear growth. Frontiers in Endocrinology 20112 95. (https://doi.org/10.3389/fendo.2011.00095)

3 Bach LA. IGF-binding proteins. Journal of Molecular Endocrinology 201861 T11-T28. (https://doi.org/10.1530/JME-17-0254)

4 Ooi GT, Cohen FJ, Tseng LY, Rechler MM \& Boisclair YR. Growth hormone stimulates transcription of the gene encoding the acidlabile subunit (ALS) of the circulating insulin-like growth factorbinding protein complex and ALS promoter activity in rat liver. Molecular Endocrinology 199711 997-1007. (https://doi.org/10.1210/ mend.11.7.9942)

5 Cohen P, Rogol AD, Deal CL, Saenger P, Reiter EO, Ross JL, Chernausek SD, Savage MO, Wit JM \& ISS Consensus Workshop participants. Consensus statement on the diagnosis and treatment of children with idiopathic short stature: a summary of the Growth Hormone Research Society, the Lawson Wilkins Pediatric Endocrine Society, and the European Society for Paediatric Endocrinology Workshop. Journal of Clinical Endocrinology and Metabolism 200893 4210-4217. (https://doi.org/10.1210/ jc.2008-0509)

6 Stanley T. Diagnosis of growth hormone deficiency in childhood. Current Opinion in Endocrinology, Diabetes, and Obesity 201219 47-52. (https://doi.org/10.1097/MED.0b013e32834ec952)

7 Ranke MB, Schweizer R, Elmlinger MW, Weber K, Binder G, Schwarze CP \& Wollmann HA. Relevance of IGF-I, IGFBP-3, and IGFBP-2 measurements during GH treatment of GH-deficient and non-GH-deficient children and adolescents. Hormone Research 2001 55 115-124. (https://doi.org/10.1159/000049982)

8 Cianfarani S, Bonfanti R, Bitti ML, Germani D, Boemi S, Chiumello G \& Boscherini B. Growth and insulin-like growth factors (IGFs) in children with insulin-dependent diabetes mellitus at the onset of disease: evidence for normal growth, age dependency of the IGF system alterations, and presence of a small (approximately 18-kilodalton) IGF-binding protein-3 fragment in serum. Journal of Clinical Endocrinology and Metabolism $2000 \mathbf{8 5}$ 4162-4167. (https://doi.org/10.1210/jcem.85.11.6996)

9 Cianfarani S, Liguori A, Boemi S, Maghnie M, Iughetti L, Wasniewska M, Street ME, Zucchini S, Aimaretti G \& Germani D. Inaccuracy of insulin-like growth factor (IGF) binding protein (IGFBP)-3 assessment in the diagnosis of growth hormone (GH) deficiency from childhood to young adulthood: association to low GH dependency of IGF-II and presence of circulating IGFBP-3 18-kilodalton fragment. Journal of Clinical Endocrinology and Metabolism 200590 6028-6034. (https://doi.org/10.1210/jc.20050721)

10 Baxter RC. Insulin-like growth factor (IGF)-binding proteins: interactions with IGFs and intrinsic bioactivities. American Journal of Physiology: Endocrinology and Metabolism 2000278 E967-E976. (https://doi.org/10.1152/ajpendo.2000.278.6.E967)

11 Hakuno F \& Takahashi SI. IGF1 receptor signaling pathways. Journal of Molecular Endocrinology 201861 T69-T86. (https://doi.org/10.1530/ JME-17-0311)

12 Dauber A, Munoz-Calvo MT, Barrios V, Domene HM, Kloverpris S, Serra-Juhe C, Desikan V, Pozo J, Muzumdar R, Martos-Moreno GÁ et al. Mutations in pregnancy-associated plasma protein A2 cause short stature due to low IGF-I availability. EMBO Molecular Medicine 20168 363-374. (https://doi.org/10.15252/ emmm.201506106) 
13 Cabrera-Salcedo C, Mizuno T, Tyzinski L, Andrew M, Vinks AA, Frystyk J, Wasserman H, Gordon CM, Hwa V, Backeljauw P et al. Pharmacokinetics of IGF-1 in PAPP-A2-deficient patients, growth response, and effects on glucose and bone density. Journal of Clinical Endocrinology and Metabolism 2017102 4568-4577. (https://doi. org/10.1210/jc.2017-01411)

14 Overgaard MT, Boldt HB, Laursen LS, Sottrup-Jensen L, Conover CA \& Oxvig C. Pregnancy-associated plasma protein-A2 (PAPP-A2), a novel insulin-like growth factor-binding protein-5 proteinase. Journal of Biological Chemistry 2001276 21849-21853. (https://doi. org/10.1074/jbc.M102191200)

15 Oxvig C. The role of PAPP-A in the IGF system: location, location, location. Journal of Cell Communication and Signaling 20159 177-187. (https://doi.org/10.1007/s12079-015-0259-9)

16 Kloverpris S, Gaidamauskas E, Rasmussen LC, Overgaard MT, Kronborg C, Knudsen UB, Christiansen M, Kumar A \& Oxvig C. A robust immunoassay for pregnancy-associated plasma protein-A2 based on analysis of circulating antigen: establishment of normal ranges in pregnancy. Molecular Human Reproduction 201319 756-763. (https://doi.org/10.1093/molehr/gat047)

17 Steinbrecher A, Janke J, Poy MN, Oxvig C \& Pischon T. Pregnancyassociated plasma protein-A2 and anthropometry, lifestyle, and biochemical factors in a human adult population. Scientific Reports 20177 10455. (https://doi.org/10.1038/s41598-017-10629-y)

18 Baye TM, Butsch Kovacic M, Biagini Myers JM, Martin LJ, Lindsey M, Patterson TL, He H, Ericksen MB, Gupta J, Tsoras AM et al. Differences in candidate gene association between European ancestry and African American asthmatic children. PLoS ONE 20116 e16522. (https://doi.org/10.1371/journal.pone.0016522)

19 Kovacic MB, Myers JM, Wang N, Martin LJ, Lindsey M, Ericksen MB, He H, Patterson TL, Baye TM, Torgerson D et al. Identification of KIF3A as a novel candidate gene for childhood asthma using RNA expression and population allelic frequencies differences. PLOS ONE 20116 e23714. (https://doi.org/10.1371/journal.pone.0023714)

20 Mersha TB, Martin LJ, Biagini Myers JM, Kovacic MB, He H, Lindsey M, Sivaprasad U, Chen W \& Khurana Hershey GK. Genomic architecture of asthma differs by sex. Genomics 2015106 15-22. (https://doi.org/10.1016/j.ygeno.2015.03.003)

21 Dolan LM, Bean J, D'Alessio D, Cohen RM, Morrison JA, Goodman E \& Daniels SR. Frequency of abnormal carbohydrate metabolism and diabetes in a population-based screening of adolescents. Journal of Pediatrics 2005146 751-758. (https://doi.org/10.1016/j. jpeds.2005.01.045)

22 Kuczmarski RJ, Ogden CL, Grummer-Strawn LM, Flegal KM, Guo SS, Wei R, Mei Z, Curtin LR, Roche AF \& Johnson CL. CDC growth charts: United States. Advance Data 2000314 1-27.

23 Flegal KM \& Cole TJ. Construction of LMS parameters for the Centers for Disease Control and Prevention 2000 growth charts. National Health Statistics Reports 201363 1-3.

24 Stasinopoulos MD, Rigby RA, Heller GZ, Voudouris V \& De Bastiani F. Flexible Regression and Smoothing: Using Gamlss in R. New York: Chapman \& Hall/CRC, 2017.

25 Grimberg A, DiVall SA, Polychronakos C, Allen DB, Cohen LE, Quintos JB, Rossi WC, Feudtner C, Murad MH \& Drug and Therapeutics Committee and Ethics Committee of the Pediatric Endocrine Society. Guidelines for growth hormone and insulinlike growth factor-I treatment in children and adolescents: growth hormone deficiency, idiopathic short stature, and primary insulinlike growth factor-I deficiency. Hormone Research in Paediatrics 2016 86 361-397. (https://doi.org/10.1159/000452150)

26 Bidlingmaier M, Friedrich N, Emeny RT, Spranger J, Wolthers OD, Roswall J, Korner A, Obermayer-Pietsch B, Hubener C, Dahlgren J et al. Reference intervals for insulin-like growth factor-1 (igf-i) from birth to senescence: results from a multicenter study using a new automated chemiluminescence IGF-I immunoassay conforming to recent international recommendations. Journal of Clinical
Endocrinology and Metabolism 201499 1712-1721. (https://doi. org/10.1210/jc.2013-3059)

27 Juul A, Bang P, Hertel NT, Main K, Dalgaard P, Jorgensen K, Muller J, Hall K \& Skakkebaek NE. Serum insulin-like growth factor-I in 1030 healthy children, adolescents, and adults: relation to age, sex, stage of puberty, testicular size, and body mass index. Journal of Clinical Endocrinology and Metabolism 199478 744-752. (https://doi. org/10.1210/jcem.78.3.8126152)

28 Kawai N, Kanzaki S, Takano-Watou S, Tada C, Yamanaka Y, Miyata T, Oka M \& Seino Y. Serum free insulin-like growth factor I (IGF-I), total IGF-I, and IGF-binding protein-3 concentrations in normal children and children with growth hormone deficiency. Journal of Clinical Endocrinology and Metabolism 199984 82-89. (https://doi. org/10.1210/jcem.84.1.5407)

29 Isojima T, Shimatsu A, Yokoya S, Chihara K, Tanaka T, Hizuka N, Teramoto A, Tatsumi KI, Tachibana K, Katsumata N et al. Standardized centile curves and reference intervals of serum insulinlike growth factor-I (IGF-I) levels in a normal Japanese population using the LMS method. Endocrine Journal 201259 771-780. (https:// doi.org/10.1507/endocrj.ej12-0110)

30 Hyun SE, Lee BC, Suh BK, Chung SC, Ko CW, Kim HS, Lee KH, Yang SW, Shin CH, Hwang JS et al. Reference values for serum levels of insulin-like growth factor-I and insulin-like growth factor binding protein-3 in Korean children and adolescents in Korean. Clinical Biochemistry 201245 16-21. (https://doi.org/10.1016/j. clinbiochem.2011.10.003)

31 Nimura A, Katsumata N \& Tanaka T. Serum levels of free insulinlike growth factor (IGF)-I in normal children. Clinical Pediatric Endocrinology 200413 71-78. (https://doi.org/10.1297/cpe.13.71)

32 Juul A, Holm K, Kastrup KW, Pedersen SA, Michaelsen KF, Scheike T, Rasmussen S, Muller J \& Skakkebaek NE. Free insulin-like growth factor I serum levels in 1430 healthy children and adults, and its diagnostic value in patients suspected of growth hormone deficiency. Journal of Clinical Endocrinology and Metabolism 199782 2497-2502. (https://doi.org/10.1210/jcem.82.8.4137)

33 Hasegawa Y, Hasegawa T, Takada M \& Tsuchiya Y. Plasma free insulinlike growth factor I concentrations in growth hormone deficiency in children and adolescents. European Journal of Endocrinology 1996134 184-189. (https://doi.org/10.1530/eje.0.1340184)

34 Hasegawa Y, Hasegawa T, Fujii K, Konii H, Anzo M, Aso T, Koto S, Takada M \& Tsuchiya Y. High ratios of free to total insulin-like growth factor-I in early infancy. Journal of Clinical Endocrinology and Metabolism 199782 156-158. (https://doi.org/10.1210/ jcem.82.1.3679)

35 Hasegawa T, Hasegawa Y, Takada M \& Tsuchiya Y. The free form of insulin-like growth factor I increases in circulation during normal human pregnancy. Journal of Clinical Endocrinology and Metabolism 199580 3284-3286. (https://doi.org/10.1210/jcem.80.11.7593439)

36 Clemmons DR. Role of IGF-binding proteins in regulating IGF responses to changes in metabolism. Journal of Molecular Endocrinology 201861 T139-T169. (https://doi.org/10.1530/JME18-0016)

37 Friedrich N, Wolthers OD, Arafat AM, Emeny RT, Spranger J, Roswall J, Kratzsch J, Grabe HJ, Hubener C, Pfeiffer AF et al. Age- and sex-specific reference intervals across life span for insulin-like growth factor binding protein 3 (IGFBP-3) and the IGF-I to IGFBP-3 ratio measured by new automated chemiluminescence assays. Journal of Clinical Endocrinology and Metabolism 201499 1675-1686. (https:// doi.org/10.1210/jc.2013-3060)

38 Hasegawa Y, Hasegawa T, Aso T, Kotoh S, Tsuchiya Y, Nose O, Ohyama Y, Araki K, Tanaka T, Saisyo Set al. Usefulness and limitation of measurement of insulin-like growth factor binding protein-3 (IGFBP-3) for diagnosis of growth hormone deficiency. Endocrinologia Japonica 199239 585-591.

39 Quigley CA, Zagar AJ, Liu CC, Brown DM, Huseman C, Levitsky L, Repaske DR, Tsalikian E \& Chipman JJ. United States multicenter 
study of factors predicting the persistence of GH deficiency during the transition period between childhood and adulthood. International Journal of Pediatric Endocrinology 20132013 6. (https:// doi.org/10.1186/1687-9856-2013-6)

40 Wang J, Qiu Q, Haider M, Bell M, Gruslin A \& Christians JK. Expression of pregnancy-associated plasma protein A2 during pregnancy in human and mouse. Journal of Endocrinology 2009202 337-345. (https://doi.org/10.1677/JOE-09-0136)

41 Renes JS, van Doorn J \& Hokken-Koelega AC. Ternary complex formation and IGFBP-3 proteolytic activity during childhood: age- dependent changes. Journal of Clinical Endocrinology and Metabolism 201499 E1988-E1996. (https://doi.org/10.1210/jc.2013-3814)

42 Frystyk J, Vestbo E, Skjaerbaek C, Mogensen CE \& Orskov H. Free insulin-like growth factors in human obesity. Metabolism: Clinical and Experimental 199544 (Supplement 4) 37-44. (https://doi. org/10.1016/0026-0495(95)90219-8)

43 Frystyk J, Brick DJ, Gerweck AV, Utz AL \& Miller KK. Bioactive insulin-like growth factor-I in obesity. Journal of Clinical Endocrinology and Metabolism 200994 3093-3097. (https://doi.org/10.1210/ jc.2009-0614)

Received 23 October 2019

Revised version received 30 December 2019

Accepted 21 January 2020 